\section{Don't punish scientists for government actions}

Sir-You mention in News in Brief (Nature 416, 574; 2002) a letter from 125 academics published in the UK national newspaper The Guardian, urging a suspension in European funding for Israeli research programmes.

Richard Dawkins, a signatory of that letter, once notoriously advised the Prince of Wales: "Of course we must be openminded, but not so open-minded that our brains drop out." With this in mind, I would like to point out to the 125 distinguished signatories that Israel is not a freeloading recipient of European research funds, but rather a participating country that pays a designated contribution to the overall budget of the European Union (EU).

A suspension of our 'associated nation' status in the EU will free our government from the obligation to transfer these funds to the EU. Because academic research and academic freedom are not priorities of the Sharon government, to put it mildly, the net result will be a punitive blow to Israeli researchers (not a group noted for blind support of the government), while freeing up funds that the Sharon government will undoubtedly channel into defence needs.

Perhaps the 125 Guardian authors need to bear in mind another (slightly modified) quotation, "put brain into gear before setting pen to paper”.

Mike Fainzilber

Department of Biological Chemistry, Weizmann Institute of Science, 76100 Rehovot, Israel

\section{The challenge offered by X-ray lasers}

Sir-In his Correspondence "Excitement over X-ray lasers is excessive" (ref. 1), responding to your News Feature ${ }^{2}$ about the applications of X-ray free-electron lasers (FELs), Richard Henderson raises two points. First, that the development of $\mathrm{X}$-ray FELs for biological applications threatens the field of structural biology because it will use up money needed for existing techniques; and second, that the development of existing techniques will be more fruitful than investing in an expensive, unproven technology such as X-ray FELs. I believe that both of these arguments are incorrect.

Synchrotron machines were developed by physicists and materials scientists, and have evolved to benefit biology. When the first dedicated synchrotron light sources came to life more than 20 years ago, they produced $\mathrm{X}$-rays with intensities
50-100 times greater than a rotating anode generator. Yet synchrotron radiation triggered a revolution in the life sciences, and today almost 15,000 $\mathrm{X}$-ray structures feature in the protein data bank as a result.

Did the construction of synchrotrons harm biology? Certainly not. Should one be afraid of a much bigger step ahead when the first X-ray FEL comes to life? I don't think so.

If one takes the speed of walking and multiplies it by $10^{10}$, the result is a speed 100 times faster than the speed of light. The expected improvement in peak brilliance offered by X-ray FELs over existing synchrotrons is of this magnitude. These machines will bring us into a world for which only predictions exist.

A lack of hands-on experimental data on the behaviour of matter under these conditions makes very detailed forecasts difficult. But one thing is certain: $\mathrm{X}$-ray FELs will generate fresh thinking, new science and a new scientific community. To imply that there is nothing that X-ray FELs can discover in biology is misguided.

The money for building and running the Linac Coherent Light Source at Stanford (first of the planned X-ray FELs) will come from the US Department of Energy. These funds have no direct 'crossover' to biomedical research or biology. Every one of the five synchrotron $\mathrm{X}$-ray sources in the United States was built and is operated by agencies that do not deal with biology.

One can make arguments for the advantages of using electrons, as outlined by Henderson, or others for using X-ray pulses. One can estimate that the conventional handicap of X-rays over electrons could be reversed ${ }^{3}$ and made into a net gain on very small samples, when extremely intense and very short X-ray pulses will be produced. This is the domain of the X-ray FELs.

There is surely room for more than one avenue to be explored - different techniques will be appropriate for different biological structures and processes. This flexibility is intrinsic to the nature of research and essential for scientific progress. There are no threats here, only challenges.

\section{Janos Hajdu}

Biomedical Center, Uppsala University, Box 576, S-751 23 Uppsala, Sweden

1. Henderson, R. Nature 415, 833 (2002).

2. Patel, N. Nature 415, 110-111 (2002).

3. Neutze, R., Wouts, R., van der Spoel, D., Weckert, E. \& Hajdu, J. Nature 406, 752-757 (2000).

\title{
Intensive farming, US-style, is not sustainable worldwide
}

\author{
More greenhouse gases will increase loss of usable land.
}

Sir - Stephen Budiansky in his

Correspondence "How affluence could be good for the environment" calculates that, thanks to increased crop yields, the 'ecological footprint' of North Americans is much smaller than that calculated by the World Wide Fund for Nature. He touches on the inclusion of per capita greenhouse-gas emissions, but he overlooks the impact of intensive crop production on emissions of the non- $\mathrm{CO}_{2}$ greenhouse gases methane $\left(\mathrm{CH}_{4}\right)$ and nitrous oxide $\left(\mathrm{N}_{2} \mathrm{O}\right)$.

Agricultural soils and livestock farming already emit around 7 million tonnes of nitrogen as $\mathrm{N}_{2} \mathrm{O}$ to the atmosphere each year ${ }^{2}$; worldwide nitrogen-fertilizer applications at the rate Budiansky suggests as typical for the United States (115 $\mathrm{kg} \mathrm{ha}^{-1}$ ) would lead to further increases. Similarly, agriculture around the world constitutes a source of more than 100 million tonnes of methane each year - more intensive farming is likely to increase this methane source, while at the same time increased global nitrogen application and deposition may greatly reduce the soil methane sink (about $30 \mathrm{Tg}$ $\mathrm{CH}_{4} \mathrm{yr}^{-1}$; ref. 3).

Budiansky argues that, with more intensive farming methods and as countries become wealthier, the world's population could significantly increase per capita consumption without increased land requirements.

I doubt whether he has included in his calculations the loss of usable land owing to sea-level rise, as predicted by the Intergovernmental Panel on Climate Change, and to desertification resulting from global warming ${ }^{4}$.

David S. Reay Institute of Ecology and Resource Management, University of Edinburgh,

Edinburgh EH6 3JU, UK

1. Budiansky, S. Nature 416, 581 (2002).

2. Kroeze, C. A, Mosier, A. R. \& Bouwman, L. Global Biogeochem. Cycles 13, 1-8 (1999).

3. Mosier, A. R. et al. Climatic Change 40, 39-80 (1998).

4. IPCC. Climate Change 2001: The Scientific Basis (Cambridge Univ. Press, 2001). 